\title{
DO TRÁFICO DE ESCRAVOS À INTERNET: ROTAS SUL-ATLÂNTICAS, INTEGRAÇÃO TERRITORIAL E A NASCENTE GEOGRAFIA DOS CABOS SUBMARINOS ENTRE O BRASIL E O CONTINENTE AFRICANO
}

\author{
FROM SLAVERY TRADE TO THE INTERNET: SOUTH-ATLANTIC ROUTES, \\ TERRITORIAL INTEGRATION AND THE RISING GEOGRAPHY OF \\ SUBMARINE CABLES BETWEEN BRAZIL AND THE AFRICAN CONTINENT
}

\author{
DEL TRÁFICO DE ESCLAVOS A LA INTERNET: RUTAS SUR-ATLÁNTICAS, \\ INTEGRACIÓN TERRITORIAL Y LA NACIENTE GEOGRAFÍA DE LOS \\ CABLES SUBMARINOS ENTRE EL BRASIL Y EL CONTINENTE AFRICANO
}

Antonio Gomes de Jesus Neto - An Academic Network at São Paulo - São Paulo - São Paulo - Brasil antoniogjneto@yahoo.com.br

\section{Resumo}

Pelos cabos submarinos de fibra ótica passa, hoje, a quase totalidade do tráfego de internet em escala mundial. A profusão destes cabos pelos principais oceanos passa também pelo Atlântico Sul, onde atualmente estão instalados, ou em projeto, 4 cabos conectando diretamente o Brasil à África. Uma análise das rotas selecionadas sugere, porém, a continuidade geográfica de um longo processo histórico de integração territorial que se iniciou de maneira violenta com o tráfico de escravos ainda no século XVI. Da mesma maneira, foram sempre alguns poucos agentes privados, apoiados por Estados-nacionais, os principais operadores desta integração, que apesar de inicialmente violenta hoje se insere no assim denominado processo de Cooperação Sul-Sul.

Palavras-chave: Cabos submarinos, integração territorial, Brasil-África, Atlântico Sul.

\section{Abstract}

Currently, almost the entire totality of global Internet traffic passes through optic fiber submarine cables. The profusion of these cables throughout the oceans includes the South Atlantic, where there are four installed or designed cables connecting Brazil directly to Africa. The selected routes suggest the geographic continuity of a long historical process of territorial integration that has started violently in the $16^{\text {th }}$ century with the Atlantic slavery trade. Likewise, a few private entrepreneurs supported by National States have always been the main agents of an integration that, despite its violent beginning, is now part of the so-called South-South Cooperation process.

Keywords: Submarine cables, territorial integration, Brazil-Africa, South Atlantic.

\section{Resumen}

Por los cables submarinos pasa hoy la casi totalidad del tráfico web global. La profusión de estos cables por los océanos incluye el Atlántico Sur, donde actualmente están instalados 0 en proyecto 4 cables que conectan directamente Brasil y África. Sin embargo, un análisis de las rutas seleccionadas sugiere la continuidad geográfica de un largo proceso histórico de integración territorial, que comenzó violentamente con el tráfico de esclavos en el siglo XVI. También, algunos pocos agentes privados apoyados por los Estados nacionales fueran históricamente los principales operadores de dicha integración, que a pesar de su origen violento hoy se denomina Cooperación Sur-Sur.

Palabras-clave: cables submarinos, integración territorial, Brasil-África, Atlántico Sur. 


\section{Introdução'}

É consensual que os primeiros contatos entre a formação socioespacial (Santos, 1977) brasileira e suas correlatas africanas datam do século XVI, com o início de um processo conhecido como "tráfico atlântico de escravos" (Almeida, 2017, p. 447), que teve no transporte marítimo seu principal condutor. Quatro séculos depois, foi apenas após a I Guerra Mundial que, pela primeira vez, pôde-se atravessar o Oceano Atlântico por outro meio que não a navegação marítima, e com o advento do transporte aéreo configurou-se uma estrutura de integração territorial entre o Brasil e os Estados africanos fundamentalmente baseada em portos, aeroportos, rotas marítimas e rotas aéreas.

Já é realidade, porém, uma nova modalidade de integração entre esses territórios, relacionada agora não mais apenas à questão da circulação, mas também à comunicação entre eles. Desde o início dos anos 2000, grandes empresas de telecomunicações organizam-se para a construção de infraestruturas de internet (como cabos submarinos e data centers) interligando o Brasil com Angola, África do Sul, Cabo Verde, Camarões e Senegal, tendo a cidade de Fortaleza, no Ceará, como ponto nodal $(h u b)$ de conexão e integração informacional entre o território brasileiro e o continente africano ${ }^{2}$.

Considerados hoje infraestruturas críticas para o funcionamento da economia em escala global (Davenport, 2012), pelos cabos submarinos de fibra ótica trafegam informações essenciais que asseguram, em tempo real, operações financeiras bilionárias, operações produtivas que podem coordenar dezenas de locais de produção em diferentes países, pesquisas científicas de alta tecnologia e elementos-chave da segurança nacional dos Estados. Tal importância adquirida pela informação na economia internacional corrobora a visão de Santos (1994, p. 17) ao reconhecê-la como "o verdadeiro instrumento de união" dos territórios na contemporaneidade, de modo que, pensar a integração territorial entre o Brasil e os Estados africanos implica, necessariamente, pensar uma integração informacional baseada na internet e nos seus cabos submarinos de fibra ótica. 
A internet e o espaço geográfico: a geografia dos cabos submarinos

Ao contrário de sua fluidez ostensiva, a geografia da Internet reflete a geografia da Terra; prende-se às fronteiras das nações e às margens dos continentes. (Blum, 2012, p. 36).

Hoje amplamente contestada na Geografia, a ideia de que a interconectividade em escala mundial possibilitada pelo advento da internet diminuiria, ou até suprimiria, a importância do espaço geográfico deixou como importante contribuição teórica o conceito de "ciberespaço". Discutido com diferentes graus de crítica por autores como Malecki (2002) e Motta (2012), há um consenso em entender o ciberespaço como o componente virtual (e mesmo imaterial) da internet, de modo que, mesmo invocando uma dimensão espacial em sua denominação, não são consideradas as infraestruturas físicas e as relações político-econômicas necessárias a essa circulação mundial da informação. Contudo, resgatando o conceito de "espaço geográfico" definido por Santos (1996, p. 63) como um "conjunto indissociável [...] de sistemas de objetos e sistemas de ações", tais dimensões parecem fundamentais para entender a denominada Geografia da Internet.

Pensando-a primeiramente como um sistema de objetos, pode-se definir a internet como uma rede de transmissão física de dados entre diferentes pontos do espaço geográfico. Grosso modo, esses dados transmitidos nada mais são do que informações transformadas em linguagem binária ${ }^{3}$ e agrupadas nos chamados "pacotes de dados", que viajam de um ponto a outro do espaço geográfico por condutores físicos variados, de acordo com a tecnologia adotada. Como discutido em Warf (2006), essa troca de dados em escala mundial é possibilitada hoje, fundamentalmente, por dois sistemas técnicos complementares e concorrentes: os satélites e os cabos submarinos de fibra ótica.

Fazendo um percurso histórico desta transmissão internacional de dados, o geógrafo estadunidense aponta uma predominância dos satélites até meados dos anos 1980, sugerindo uma ligação entre sua decadência (e a consequente proliferação de empresas privadas do setor de fibra ótica) com a emergência do paradigma neoliberal e a concomitante emergência da internet como variável fundamental do sistema econômico mundial. Os detalhes técnicos de ambas as tecnologias são bastante complexos e podem ser melhor compreendidos em Tanenbaum (2003), mas com o 
desenvolvimento de tecnologias como novos repetidores oceânicos de sinal e o chamado DWDM ${ }^{4}$, a capacidade de transmissão de dados dos cabos de fibra ótica tornou quase impossível a competição por parte dos satélites, fazendo com que hoje trafeguem pelos cabos submarinos cerca de 95\% dos pacotes de dados informacionais em escala global (Clark, 2016).

Os cabos submarinos de fibra ótica são, contudo, apenas um dos objetos técnicos necessários ao funcionamento da internet, ligando-se, assim, a um conjunto de outros tipos de cabos e fixos geográficos de maneira sistêmica. Nos pontos de aterragem desses cabos submarinos ${ }^{5}$, geralmente há uma estação onde o cabo se conecta a outros cabos e a outras estações maiores com centenas ou milhares de roteadores, convencionalmente chamadas de pontos de troca de tráfego (PTTs). Fundamentais no surgimento e expansão da internet nos EUA (Blum, 2012), esses fixos geográficos funcionam como "rodoviárias" onde os cabos aportam e redirecionam os pacotes de dados por meio de outros cabos, que por sua vez têm também diferentes configurações e funções, evidenciando mais ainda a constituição sistêmica de objetos da internet.

Entre o ponto de aterragem localizado na costa e um grande PTT, os dados passam por um cabo de ligação denominado backhaul (Malecki; Wei, 2009), e é por meio desse sistema que o cabo submarino se conecta ao backbone nacional (MOTTA, 2012), espécie de espinha dorsal da internet de um território nacional. Em grandes metrópoles, para além desses tipos de cabos mencionados, geralmente existem também redes metropolitanas anelares que circundam toda a mancha urbana para proporcionar redundância e garantir conectividade a um número muitas vezes milionário de usuários.

Simultaneamente a um sistema de objetos, a internet é também, como parte do espaço geográfico definido por Santos (1996), um conjunto de sistemas de ação. Isto implica, portanto, um conjunto de agentes e um sistema político-normativo que possibilitam a esses objetos técnicos realizarem suas funções. No caso dos cabos submarinos de fibra ótica, os agentes envolvidos são historicamente grandes corporações internacionais que se articulam na fabricação, pesquisa, instalação e operação dos cabos, e que não raro se envolvem em conflitos e negociações com os Estados nacionais por onde esses cabos passam ou aterram.

Conforme Davenport (2012) e Van Logchem (2014), a mediação destes conflitos e o sistema regulatório internacional que incide sobre todas as etapas de operação dos cabos submarinos estão previstos na 
Convenção das Nações Unidas sobre o Direito do Mar (CNUDM), de 1982, que basicamente divide e define áreas marítimas por todo o globo em três grandes tipos principais: (1) o mar territorial; (2) a plataforma continental e as zonas econômicas exclusivas (ZEEs); e (3) o alto-mar. Baseada nos princípios jurídicos do "bom senso"6 e da "liberdade" de instalação dos cabos, a convenção faz uma espécie de gradação do nível de regulação à qual os Estados podem sujeitar a operação privada dos cabos submarinos, desde uma maior soberania no mar territorial ${ }^{7}$ até uma quase total liberdade no alto-mar, passando pela região mais ambígua de plataformas continentais ${ }^{8}$ e ZEEs, onde a soberania dos Estados e a liberdade das corporações entram constantemente em conflito.

Para fazer valer esses dispositivos encontrados na CNUDM, destacam-se instrumentos regulatórios, como as permissões e notificações (Van Logchem, 2014), reivindicados por Estados ou corporações conforme seus interesses. Geralmente acionadas em disputas nas plataformas continentais e ZEEs (mas também no mar territorial), as permissões são documentos que os Estados exigem para que as corporações operem em áreas marítimas onde vigora sua soberania; por outro lado, as corporações defendem o uso de simples notificações, sem precisar submeter-se à aprovação ou desaprovação dos Estados. Outra forma de equacionar esses conflitos são os "corredores de cabos submarinos", inspirados nos tradicionais corredores de transporte e desenhados em torno das rotas dos cabos, funcionando como zonas oficiais de proteção destes, o que já existe em alguns países do leste asiático (Davenport, 2012).

Todo este conjunto de sistemas de objetos e de sistemas de ações da internet tem nesta relação entre o público e o privado seu conflito essencial, amplamente debatido por diversos autores. Em resumo, as discussões dividem-se entre aquelas clamando por menos entraves e uma maior agilidade na operação dos cabos submarinos, sugerindo menos regulação, apesar do discurso mais ponderado (Davenport, 2012; Van Logchem, 2014); e aquelas, sobretudo estadunidenses, reivindicando uma maior intervenção e controle sobre os cabos por parte dos Estados, argumentando questões de soberania e segurança nacional (Sechrist, 2010; Clark, 2016). De qualquer maneira, por serem detentores de toda a infraestrutura física, grandes consórcios privados são os principais agentes de operação dos cabos submarinos de fibra ótica, colocando a discussão mais em termos de governança corporativa (Dowbor, 2017) do que de 
uma regulação híbrida do território (Antas Junior, 2005), onde Estados e corporações dividiriam tal tarefa.

O caso dos cabos submarinos de fibra ótica entre o Brasil e o continente africano não foge à regra, e são fundamentalmente consórcios privados (com maior ou menor ligação com seus Estados de origem) os responsáveis pelo projeto e operação desses cabos nos últimos anos. Pensando historicamente, esse modelo de integração territorial executado pelo setor privado com apoio dos Estados sempre foi o predominante nas relações entre a formação socioespacial brasileira e suas correlatas africanas, e uma recuperação histórica desse oscilante movimento de aproximação mostra, mesmo com nuances, que as rotas atualmente desenhadas para os cabos submarinos seguem o mesmo padrão vigente desde o início do tráfico de escravos, ainda no século XVI.

\section{A integração territorial Brasil-África: do tráfico atlântico de escravos à internet}

[...] a reconstrução dos sucessivos sistemas temporais e dos sistemas espaciais sucessivos é um dado fundamental quando se busca uma explicação para as situações atuais. (Santos, [1978] 2002, p. 255).

[...] o conhecimento dos sistemas técnicos sucessivos é essencial para o entendimento das diversas formas históricas de estruturação, funcionamento e articulação dos territórios. (Santos, 1996, p. 171).

Em diferentes passagens de duas das principais obras de sua trajetória acadêmica, o geógrafo Milton Santos ([1978] 2002; 1996) chama a atenção ao papel nada acessório que a História possui nas intepretações geográficas do mundo contemporâneo. No caso da internet e dos cabos submarinos de fibra ótica que a estruturam, analisar a sucessão dos sistemas técnicos de integração entre o Brasil e o continente africano é fundamental para compreender o porquê das atuais rotas e pontos de aterragem escolhidos para esses cabos submarinos nas margens dos dois continentes. Assim, a atual geografia da internet se insere inevitavelmente na história de um sistema econômico com quase cinco séculos de desdobramentos e deslocamentos (Arrighi, 1996), articulando lugares e agentes em um movimento totalizante, como Santos (1996) defendeu ser lido qualquer fenômeno geográfico. 
Existem em operação, atualmente, dois cabos submarinos de fibra ótica entre o Brasil e o continente africano, além de mais um já instalado e outro em projeto. Ainda que com uma capacidade muito reduzida para os padrões atuais de tráfego, o cabo Atlantis-2, ligando Fortaleza a Lisboa (em Portugal), entrou em operação em 2000 e foi o primeiro cabo submarino de fibra ótica a ligar a costa brasileira à africana, uma vez que tem pontos de aterragem em Praia (Cabo Verde) e Dakar (Senegal). Já os outros três cabos ligando o território brasileiro à África, melhor detalhados no próximo item deste artigo, têm como rotas: (1) Fortaleza-Sangano (em Angola), já em operação; (2) Fortaleza-Kribi (nos Camarões), já instalado; e (3) FortalezaCape Town (na África do Sul), ainda em projeto. Todos os cabos citados (Mapa 1) refazem, com maior ou menor exatidão, as rotas históricas de contato do Brasil com a África, desde o início do tráfico atlântico de escravos e passando também pelo incremento das trocas comerciais a partir da década de 1960.

Se o primeiro cabo submarino de fibra ótica a ligar os dois continentes tem como ponto de aterragem Cabo Verde e Senegal, foi também nesta região da costa africana, onde hoje se localiza o Estado de Guiné-Bissau, que começou o tráfico atlântico de escravos em direção ao Brasil, ainda no século XVI (Verger, 1987). De modo geral, tais rotas atlânticas entre as costas brasileira e africana foram "balizadas pelo vento, canalizadas pelas correntes e pautadas pelas estações” (Alencastro, [2000]2008, p. 57), ainda que para Florentino [1995](2002) a sazonalidade do tráfico respondesse mais à demanda de mão de obra escravizada, ao ciclo produtivo e às estratégias econômicas dele derivadas, do que às condições meteorológicas e de navegação propriamente ditas. 


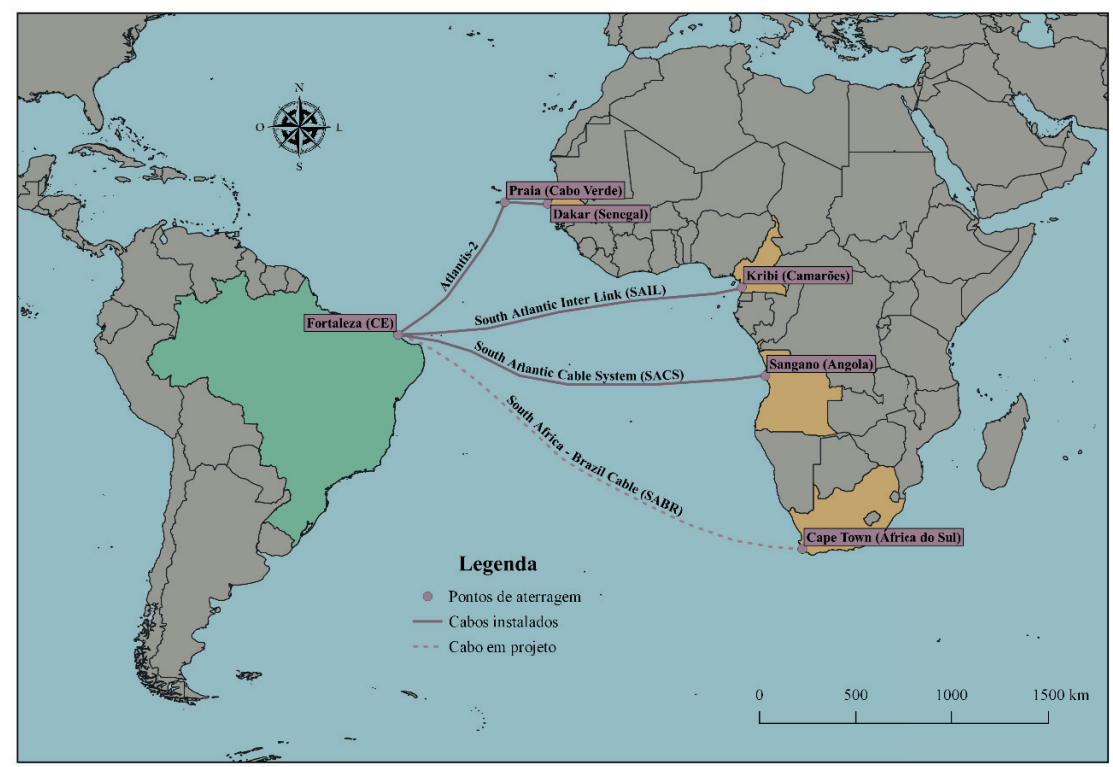

Mapa 1: Os cabos submarinos de fibra ótica entre o Brasil e o continente africano

Elaboração: Antonio Gomes de Jesus Neto (2018).

A partir do século XVII, a economia açucareira do nordeste brasileiro passou a buscar mão de obra escravizada sobretudo em Luanda, na costa angolana (Verger, 1987), configurando uma "rota aberta entre as duas margens do mar por correntezas e ventos complementares" (Alencastro, [2000]2008, p. 61). Desde então, Angola e Congo tornaram-se as regiões históricas de fornecimento de escravizados para o Brasil Colônia (Alencastro, [2000]2008; Florentino, [1995]2002), difundindo também o tráfico para portos brasileiros no Pará, Maranhão, Ceará e Rio de Janeiro.

Apesar dessa difusão do tráfico oriundo da região congo-angolana para diversos portos brasileiros, a partir do século XVIII o ciclo da mineração selou a aproximação específica da Bahia com a África Ocidental (especialmente o Golfo da Guiné), sobretudo com o porto da Costa da Mina (Gana) e a costa do Benin (Verger, 1987). Além dessas rotas, destaca-se também, já no século XIX, o início do tráfico de escravos a partir dos portos de Moçambique (no Oceano Índico), sobretudo em direção ao porto do Rio de Janeiro, que à época tornou-se o principal porto negreiro do 
Brasil Império por sua posição estratégica em relação às nascentes lavouras de café (Magalhães, 2010).

Tal estrutura, que podemos chamar de uma primeira "integração violenta" do território brasileiro com a África, era operada fundamentalmente por traficantes privados com suporte dos Estadosnacionais ${ }^{9}$, numa articulação entre os principais centros de acumulação históricos do capitalismo até o início do século XX, estudados por Arrighi (1996). Segundo Florentino [1995](2002), os navios eram propriedade privada dos traficantes, que muitas vezes os agrupavam em empresas e levavam mercadorias ${ }^{10}$ para escambo por escravizados na costa africana, influenciando as decisões do governo ${ }^{11}$ e conformando um sistema de "integração" altamente concentrado em poucas grandes empresas traficantes responsáveis pela maior parte do fluxo de mercadorias e escravizados que circulavam no Atlântico Sul.

Com o fim do tráfico em meados do século XIX, essa integração (até então violenta, necessário reforçar) entre o Brasil e o continente africano cessou até a década de 1960, sendo retomada no governo Jânio Quadros, como atestam diversos autores, como Santana (2003), Brasil (2016) e Almeida (2017). Combinando um discurso diplomático pela descolonização dos países africanos com um discurso econômico de intensificação das trocas comerciais entre os países do Sul como alternativa à crise do capitalismo, a política externa promovida pelo governo de Jânio Quadros foi responsável pela introdução do Brasil nas chamadas "relações SulSul" (Santana, 2003, p. 114), e apesar das idas e vindas durante o período militar e a redemocratização, tais relações deram a tônica do novo tipo de integração territorial entre o Brasil e os Estados africanos então em processos de independência.

Tal integração, contudo, repetia aproximadamente as rotas percorridas no tráfico atlântico de escravos, e mais uma vez eram o Senegal, o Golfo da Guiné e o sul da África (destacadamente Angola e África do Sul) os principais pontos de trocas comerciais brasileiras no continente africano ${ }^{12}$. Mais uma vez também, a integração sul-atlântica seria altamente concentrada em grandes operadores marítimos (agora multinacionais) cuja atividade foi igualmente estimulada e facilitada pelos Estados-nacionais (Santana, 2003; Lima, 2015), mas uma nova variável de integração territorial passou a coexistir com a navegação oceânica: o modal aéreo, esse sim em alguns casos operado por empresas estatais, e 
com destaque maior ao transporte de passageiros. Os principais portos e aeroportos envolvidos nessa dinâmica de integração nos últimos dez anos, a serem detalhados nos próximos parágrafos, podem ser visualizados resumidamente no Mapa 2.

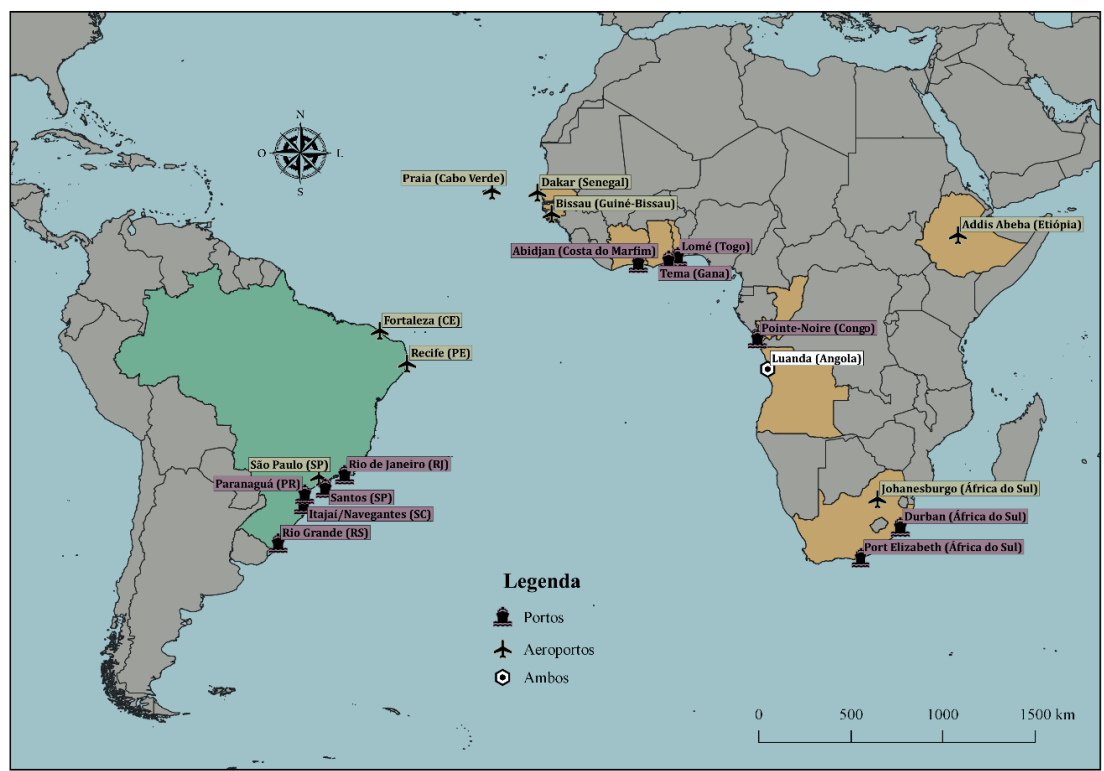

Mapa 2: Portos e aeroportos com rotas diretas entre o Brasil e a África (2008-2018)

Elaboração: Antonio Gomes de Jesus Neto (2018).

No caso da integração aérea, Santana (2003) e CNI (2008) indicam a existência e o desaparecimento, entre os anos 1970 e 1990, de voos diretos entre o Brasil e cidades como Lagos (Nigéria), Abidjan (Costa do Marfim), e Maputo (Moçambique), todas localizadas no Golfo da Guiné ou na África Austral, rotas históricas de contato entre o território brasileiro e o continente africano. Atualmente, o principal aeroporto brasileiro que se conecta com a África é o aeroporto de Guarulhos, em São Paulo, com voos diretos semanais para Johannesburgo (África do Sul) ${ }^{13}$, Luanda $\left(\right.$ Angola) ${ }^{14}$ e Addis Abeba (Etiópia) ${ }^{15}$. Além desses, destaca-se uma rota da companhia aérea cabo-verdiana TACV, ligando as cidades nordestinas brasileiras de Fortaleza e Recife à Praia (Cabo Verde), Dakar (Senegal) e Bissau (Guiné-Bissau). 
Já no caso do transporte marítimo, as rotas atualmente percorridas por operadoras marítimas multinacionais (sobretudo europeias) também não fogem do padrão histórico de integração entre o Brasil e o continente africano, e o Quadro 1 indica uma recorrência de portos localizados no Sul e Sudeste brasileiro se conectando a portos localizados no Golfo da Guiné, Angola, Congo e África do Sul (muitas vezes tendo como ponto de partida o porto de Buenos Aires, na Argentina).

Iniciado de forma violenta com o tráfico atlântico de escravos ainda no século XVI, o processo de integração territorial do Brasil com o continente africano ganhou novos contornos a partir da década de 1960, e baseadas nas antigas rotas do tráfico de escravos surgiram novas rotas comerciais - não apenas marítimas, mas também aéreas - de integração entre as duas margens do Atlântico Sul. A partir do início dos anos 2000, porém, a combinação entre uma reaproximação sem precedentes entre o governo brasileiro e os Estados africanos, a partir do governo Lula (Brasil, 2016), com a centralidade adquirida pela internet no sistema econômico mundial, como pontuado em Davenport (2012), abriu espaço para uma nova forma de integração territorial, agora baseada na informação e nos cabos submarinos de fibra ótica, ainda que inexoravelmente associada à construção histórica de rotas transoceânicas entre o Brasil e a África.

\begin{tabular}{|c|c|c|}
\hline \multicolumn{2}{|c|}{ Empresa } & \multicolumn{2}{c|}{ Portos brasileiros } & Portos africanos \\
\hline Maersk Line & $\begin{array}{c}\text { Rio Grande, Itajaí/Navegantes, Santos e } \\
\text { Rio de Janeiro }\end{array}$ & $\begin{array}{c}\text { Lomé (Togo), Pointe-Noire (Congo) e Luanda } \\
\text { (Angola) }\end{array}$ \\
\hline Hamburg Sud & $\begin{array}{c}\text { Rio Grande, Itapoá, Itajaí/Navegantes, } \\
\text { Paranaguá e Santos }\end{array}$ & Port Elizabeth (África do Sul) \\
\hline Nile Dutch & Rio de Janeiro & Pointe-Noire (Congo) \\
\hline CMA CGM & Santos & $\begin{array}{c}\text { Abidjan (Costa do Marfim), Tema (Gana), } \\
\text { Pointe-Noire (Congo) e Luanda (Angola) }\end{array}$ \\
\hline Asas Service & Rio Grande, Paranaguá e Santos & Port Elizabeth (África do Sul) \\
\hline Asas Combined & Rio Grande, Paranaguá e Santos & Port Elizabeth e Durban (África do Sul) \\
\hline
\end{tabular}

Quadro 1: Rotas marítimas diretas entre o Brasil e a costa africana entre 2008 e 2015 


\section{A nascente geografia dos cabos submarinos entre o Brasil e o continente africano ${ }^{16}$}

A geografia mundial dos cabos submarinos de fibra ótica é, antes de tudo, marcada pela grande desigualdade regional. Até pouco tempo, a oferta de infraestrutura e capacidade de tráfego nestes cabos era altamente concentrada no Atlântico Norte e no Pacífico (tendo os EUA como eixo principal), mas Malecki e Wei (2009) chamam atenção ao que eles denominaram de uma recente "virada para a Ásia”, onde a conexão entre os países do leste do continente é responsável pela maioria dos atuais cabos em construção. Concomitantemente, em um contexto de relações sem precedentes entre os Estados do Sul do mundo, como sinalizado por Fiori (2007), há também uma tendência de descentralização da construção dos cabos submarinos de fibra ótica para outras regiões do globo, e é nesse processo que aparecem os cabos interligando o Brasil e os Estados africanos.

Até então, a integração informacional entre esses territórios era, utilizando o par de conceitos proposto por Santos e Silveira (2001), muito mais viscosa do que fluida, ainda que em tempos do imaginário da velocidade (Santos, 2000) tal viscosidade seja verificada na escala dos milissegundos. Sobretudo no continente africano, onde os satélites ainda persistem como principal forma de conexão à internet (Malecki; Wei, 2009), essa viscosidade aumenta à medida que se desloca dos grandes centros urbanos em direção a cidades e áreas mais afastadas, fenômeno que em alguma medida se repete no Brasil (principalmente na Amazônia). Warf (2010, p. 45) fala, inclusive, de um "fosso digital" 17 entre a costa africana e o interior do continente, corroborando assim a análise de Santos (2000) sobre a seletividade intrínseca à fluidez verificada nos territórios.

Além de um incremento na fluidez informacional (mesmo que seletiva) entre o Brasil e o Estados africanos, é importante ter em mente também certa continuidade entre o processo de construção desses cabos e o processo histórico de integração territorial apresentado anteriormente. Assim como na estrutura do tráfico de escravizados e das trocas comerciais a partir da década de 1960, os "cabos submarinos sempre foram majoritariamente empreendimentos privados" (Malecki; Wei, 2009, p. 366, tradução nossa $)^{18}$, ainda que em todas essas formas de integração os Estados sempre tenham tido um papel crucial. Da mesma maneira, as rotas escolhidas para os cabos recentemente instalados ou em projeto 
respeitam, em maior ou menor grau, as principais rotas históricas de integração entre o Brasil e o continente africano, que segundo Alencastro [2000](2008) têm suas origens mais remotas nas condições de navegação proporcionadas pelos ventos sul-atlânticos (Mapa 1).

O primeiro desses cabos submarinos mais recentes, já em operação, é o South Atlantic Cable System (SACS), interligando a costa angolana em Sangano, ao sul de Luanda, à costa brasileira em Fortaleza. Levado a cabo pela maior empresa de telecomunicações de Angola (a Angola Cables), pelo governo japonês e pela empresa japonesa de tecnologia NEC, o cabo de $7.500 \mathrm{~km}$ é parte de um sistema mais amplo, que inclui a construção de um data center na Praia do Futuro (em Fortaleza), onde o SACS se conectará ao cabo Monet, que liga Santos a Miami passando por Fortaleza ${ }^{19}$. Além disso, a proposta em que se insere o SACS é potencializar a fluidez informacional entre toda a costa oeste da África e os EUA através do West Africa Cable System (WACS ${ }^{20}$, rota que até pouco tempo atrás só era possível passando pelo sistema de cabos europeu.

O segundo desses cabos submarinos, já instalado (e que deve entrar em operação brevemente), aproveita a histórica rota atlântica entre a costa brasileira e o Golfo da Guiné, e é parte de outra estratégia geopolítica, envolvendo diferentes agentes e objetivos. Projetado em uma parceria entre a gigante de telecomunicações China Unicom, a também chinesa Huawei Marine, o China Exim Bank, a empresa de telecomunicações camaronesa Camtel e a espanhola Telefónica, o South Atlantic Inter Link (SAIL) também aporta em Fortaleza, mas desta vez saindo da praia de Kribi, na costa sul dos Camarões. Assim como o SACS, mais do que conectar o Brasil à África, o objetivo final do SAIL é fornecer uma rota informacional da China à América Latina, passando pelo interior do continente africano (onde o país asiático também constrói infraestrutura de backbones) sem precisar passar pelos data centers da Europa e dos EUA, indicando que a referida importância atribuída à internet no sistema econômico mundial (Davenport, 2012) já começa a ganhar contornos geopolíticos explícitos.

Por fim, e ainda em fase embrionária, o último dos cabos em projeto fecha o sistema de rotas históricas e deve interligar Fortaleza a Cape Town (África do Sul), colocando também o extremo sul do continente africano no sistema brasileiro de cabos submarinos, assim como foi com o tráfico entre os portos do Rio de Janeiro e de Moçambique no século XIX, e como é hoje a principal rota aérea desta integração (São Paulo- 
Johannesburgo). Inicialmente batizado de SABR (iniciais de South Africa e Brasil), o cabo deve se interligar ao já em funcionamento Seabras-1, construído e operado pela estadunidense Seaborn Networks, que conecta diretamente as 2 principais praças financeiras das Américas: São Paulo e Nova York. Além de conectar, via Fortaleza, essas praças financeiras à principal do continente africano (Johannesburgo), o SABR também inclui um ramo para a Argentina (o ARBR), e uma conexão direta com a Índia através de um cabo construído pela indiana IOX ${ }^{21}$.

Assim, de maneira geral, os 3 mais recentes cabos submarinos de fibra ótica entre o Brasil e a costa africana são, na realidade, trechos cruciais de estratégias bem mais amplas de integração informacional em escala mundial, e apesar de se consolidarem como uma nova dimensão da Cooperação Sul-Sul, inserem-se sobretudo em arranjos econômicos e disputas geopolíticas que envolvem grandes corporações e diferentes Estados, com destaque aos Estados Unidos da América, a China e a Índia. Além disso, essas novas rotas informacionais, para além de reforçar as rotas históricas de integração entre o Brasil e o continente africano, reforçam também o papel de Fortaleza como principal hub de cabos submarinos no território brasileiro, sobretudo por sua localização geoestratégica em relação ao hemisfério norte, onde ainda se localizam grande parte dos cabos submarinos de fibra ótica em escala mundial.

\section{Considerações finais}

Do tráfico atlântico de escravos à internet, passando pelas trocas comerciais a partir dos anos 1960, a integração territorial entre a formação socioespacial brasileira e suas correlatas africanas passou historicamente por quatro rotas sul-atlânticas principais, partindo de pontos específicos do Sudeste e Nordeste brasileiro em direção: 1) à região de Senegal, Cabo Verde e Guiné-Bissau, 2) ao Golfo da Guiné, 3) Angola e Congo e 4) ao extremo sul do continente africano. Além dessa recorrência de antigas rotas, tal integração também foi quase invariavelmente um empreendimento privado, e ainda que não se possa comparar a violência do tráfico com as relações pós-1960, são sempre agentes privados seletos seus maiores beneficiados diretos. Mesmo com esse destaque aos agentes privados, não se pode esquecer também do papel sempre central dos Estados nessa integração, ora facilitando, ora estimulando, e ora regulando 
os principais operadores da circulação e comunicação dessas rotas entre o Brasil e a África.

Se a natureza comercial e privada da integração também se verifica para os cabos submarinos de fibra ótica, já é possível, contudo, vislumbrar outros usos por meio deles: através da Rede Nacional de Pesquisa (RNP), a rede acadêmica nacional do Brasil, projeta-se a utilização para pesquisa e educação de parte da banda do cabo (também atlântico) planejado para conectar a América do Sul à União Européia - o ELLAlink; e através da AmLight, consórcio pan-americano de redes acadêmicas da qual a Rede ANSP faz parte, assinou-se também um memorando de entendimento com a Angola Cables para que parte da banda do SACS seja dedicada ao uso acadêmico. Assim, e apesar da sua inquestionável importância comercial, a internet ainda pode estimular uma nova forma de integração territorial entre o Brasil e os Estados africanos, menos centrada nos grandes interesses corporativos e mais voltada aos interesses públicos e não-comerciais das populações nas duas margens do Atlântico Sul.

\section{Notas}

10 presente artigo é resultado de uma pesquisa realizada entre 2017 e 2018 no Núcleo de Aplicações em Redes Avançadas (NARA), sediado na Faculdade de Medicina da USP (FMUSP), dentro do projeto acadêmico Rede ANSP (An Academic Network at São Paulo$<$ www.ansp.br>), processo FAPESP no 17/17084-3. A Rede ANSP é uma rede acadêmica que, dentre outras atividades, provê acesso à internet às instituições de ensino e pesquisa do Estado de São Paulo.

2 Existem registros de antigos cabos telegráficos submarinos interligando o Brasil à África, mas a escassez de boas referências bibliográficas impede por ora um aprofundamento deste tipo de integração territorial.

3 Os "bits", basicamente ausência ou presença de informação (0 ou 1).

4 Do inglês Dense Wavelength Division Multiplexing.

5 Os chamados landing points, quase sempre instalados em uma praia na costa marítima.

6 Do inglês due regard.

7 Correspondente a 12 milhas náuticas, ou $22 \mathrm{~km}$, contíguas à costa marítima.

8 Correspondente a 200 milhas náuticas, ou $360 \mathrm{~km}$, contíguas à costa marítima.

9 Formalmente estabelecidos a partir do Tratado de Westphalia (1648).

10 Como tecidos, armas, tabaco, cachaça, açúcar etc. 
11 Que por sua vez, além de promulgar leis que iam ao encontro dos interesses dos traficantes, obtinham receitas do tráfico atlântico de escravos a partir de um sistema alfandegário nos portos brasileiros.

12 Santana (2003) destaca, o chamado countertrade do Brasil com Nigéria e Angola, na década de 1980, no qual esses países africanos exportavam diariamente milhares de barris de petróleo em troca de produtos ou serviços brasileiros.

13 Operado pela South African Airways e pela Latam.

14 Operado pela angolana TAAG.

15 Operado pela Ethiopian Airlines, e eventualmente fazendo escala em Lomé (no Togo). 16 Dada a atualidade do fenômeno, ainda em incipiente processo, as informações fatuais deste item foram extraídas majoritariamente de reportagens jornalísticas levantadas na internet durante os anos de 2017 e 2018, em portais como TeleSíntese, TeleGeography, Macauhub, Diário do Nordeste e Exame.

17 Do inglês digital divide.

18 No original: "Submarine cables have always been mainly private ventures" (MALECKI; WEI, 2009, p. 366).

19 Já em operação, e também construído pela Angola Cables em parceria outras corporações privadas.

20 Do qual a Angola Cables é uma das maiores acionistas.

21 Recentemente, a mesma IOX assinou um acordo de compartilhamento de capacidade com a Angola Cables, visando uma interligação também com o SACS.

\section{Referências}

ALENCASTRO, Luiz Felipe de [2000]. O trato dos viventes. Formação do Brasil no Atlântico Sul, séculos XVI e XVII. São Paulo: Companhia das Letras, 2008.

ALMEIDA, Elga Lessa de. Do outro lado do Atlântico: as relações políticas e econômicas entre o Brasil e os países africanos desde o século XX. Caderno do CEAS, Salvador/Recife, n. 241, p. 445-476, maio-ago. 2017.

ANTAS JUNIOR, Ricardo Mendes. Território e regulação: espaço geográfico, fonte material e não-formal do direito. São Paulo: Humanitas, 2005.

ARRIGHI, Giovanni. O longo século XX. Dinheiro, poder e as origens do nosso tempo. São Paulo: Contraponto/UNESP, 1996.

BLUM, Andrew. Tubos: o mundo físico da Internet. Rio de Janeiro: Rocco, 2012.

BRASIL, Henrique Gerken. Relações externas Brasil-África: da política externa independente ao governo Lula. 2016. 193 p. Dissertação (Mestrado em Filosofia)Instituto de Estudos Brasileiros, Universidade de São Paulo, São Paulo, 2016.

CLARK, Bryan. Undersea cables and the future of submarine competition. Bulletin of the Atomic Scientists, v. 72, n. 4, p. 234-237, jun. 2016. 
CONFEDERAÇÃO NACIONAL DA INDÚSTRIA (CNI). IBAS - Índia, Brasil e África do Sul. Fluxos comerciais e agenda para os serviços de transporte. Brasília: CNI, 2008. Disponível em: < http://admin.cni.org.br/portal/data/files /00/8A9015D01D92C771011D97695DDD7772/IBAS_Port_Web.pdf>. Acesso em: 21 mar. 2018.

CONVENÇÃO DAS NAÇÕES UNIDAS SOBRE O DIREITO DO MAR (CNUDM). Montego Bay (Jamaica), assinada em 10 de dezembro de 1982 (entrou em vigor em 16 de novembro de 1994). Disponível em: <http://www.un.org/depts/los/ convention_agreements/texts/unclos/unclos_e.pdf>. Acesso em: 24 nov. 2018.

DAVENPORT, Tara. Submarine communication cables and law of the sea: problems in law and practice. Ocean Development $\mathcal{E}$ International Law, v. 43, n. 3, p. 201-242, ago. 2012.

DOWBOR, Ladislau. A era do capital improdutivo: a nova arquitetura do poder - dominação financeira, sequestro da democracia e destruição do planeta. São Paulo: Outras Palavras \& Autonomia Literária, 2017.

FIORI, José Luís. A nova geopolítica das nações e o lugar da Rússia, China, Índia, Brasil e África do Sul. Revista de Economia Heterodoxa, Rio de Janeiro, ano 6, n. 8, nov. 2007.

FLORENTINO, Manolo [1995]. Em costas negras. Uma história do tráfico de escravos entre a África e o Rio de Janeiro (séculos XVIII e XIX). São Paulo: Companhia das Letras, 2002.

LIMA, Gislene Nogueira. Análise das relações comerciais do Brasil com a África durante os governos de Fernando Henrique Cardoso (1995-2002) e Luiz Inácio Lula da Silva (2003-2010). 2015. 118 p. Dissertação (Mestrado em Relações Internacionais)-Instituto de Relações Internacionais, Universidade de Brasília, Brasília, 2015.

MAGAlHÃES, Juliana de Paiva. Moçambique e Vale do Paraíba na dinâmica do comércio de escravos: diásporas e identidades étnicas, séc. XIX. 2010. 134 p. Dissertação (Mestrado em História)-Faculdade de Filosofia, Letras e Ciências Humanas (FFLCH), Universidade de São Paulo, São Paulo, 2010.

MALECKI, Edward. The Economic Geography of the Internet's Infrastructure. Economic Geography, v. 78, n. 4, p. 399-426, out. 2002.

MALECKI, Edward; WEI, Hu. A wired world: the evolving geography of submarine cables and the shift to Asia. Annals of the Association of American Geographers, Washington DC, v. 99, n. 2, p. 360-382, maio 2009.

MOTTA, Marcelo Paiva da. “Topologia dos backbones de internet no Brasil”. In: Sociedade \& Natureza, Uberlândia, v. 24, n. 1, p. 21-36, jan./abr. 2012.

SANTANA, Ivo de. Notas e comentários sobre a dinâmica do comércio BrasilÁfrica nas décadas de 1970 a 1990. Revista Brasileira de Política Internacional, Brasília, v. 46, n. 2, p. 113-137, jul./dez. 2003.

SANTOS, Milton. Sociedade e espaço: a formação social como teoria e como método. Boletim Paulista de Geografia, São Paulo, n. 54, p. 81-99, jun. 1977. 
- [1978]. Por uma geografia nova. Da crítica da Geografia a uma Geografia crítica. São Paulo: EDUSP, 2002.

. O retorno do território. In: SANTOS, Milton; SOUZA, Maria Adélia; SIILVĒEIRA, Maria Laura (Org.). Território. Globalização e fragmentação. São Paulo: Hucitec/ANPUR, 1994. Hucitec, 1996.

A natureza do espaço. Técnica e tempo. Razão e emoção. São Paulo: - Por uma outra globalização. Do pensamento único à consciência universal. Rio de Janeiro: Record, 2000.

SANTOS, Milton; SILVEIRA, Maria Laura. O Brasil: território e sociedade no início do século XXI. Rio de Janeiro: Record, 2001.

SECHRIST, Michael. Cyberspace in deep water: protecting the arteries of internet. Harvard Kennedy School, Review, Cambridge (EUA), v. 10, p. 40-44, abr. 2010.

TANENBAUM, Andrew. Redes de computadores. Rio de Janeiro: Elsevier, 2003.

VAN LOGCHEM, Youri. Submarine communication cables in disputed maritime áreas. Ocean Development \& International Law, v. 45, n. 1, p. 107-122, jan. 2014.

VERGER, Pierre. Fluxo e refluxo do tráfico de escravos entre o golfo de Benin e a Bahia de todos os Santos dos séculos XVII a XIX. São Paulo: Corrupio, 1987.

WARF, Barney. International competition between Satellite and Fiber Optic Carriers: a geographic perspective. The Professional Geographer, v. 58, n. 1, p. 1-11, fev. 2006.

. Uneven geographies of the African continent: growth, change and implications. African Geographical Review, v. 29, n. 2, p. 41-66, jan. 2010.

Antonio Gomes de Jesus Neto - Bacharel em Geografia pela Universidade de São Paulo (USP). Mestre em Geografia Humana pela Faculdade de Filosofia, Letras e Ciências Humanas da Universidade de São Paulo (FFLCH/USP). Atualmente é colaborador do Núcleo de Aplicação em Redes Avançadas (NARA) do projeto Rede ANSP (FAPESP), sediado na Faculdade de Medicina da Universidade de São Paulo (FMUSP). ORCID: $<$ https://orcid.org/0000-0001-7483-7274>.

Recebido para publicação em 2 de julho de 2018 Aceito para publicação em 7 de agosto de 2018 